\title{
On the road to inclusion: Evaluation of a refugee driver education program in regional Victoria, Australia
}

\section{Elisha Riggs}

Murdoch Childrens Research Institute

The University of Melbourne

\section{Karen Block}

The University of Melbourne

\section{Taffie Mhlanga}

Latrobe Community Health Service

\section{Christina Rush}

Latrobe Community Health Service

\section{Mollie Burley}

Monash University

\section{Commentary}

\section{Addressing social exclusion through driver education}

Social inclusion for refugees following resettlement can be hampered by language barriers, health concerns, alterations in family life, lack of relevant life skills, cultural differences, barriers to education and employment, discrimination, and housing availability (Ager \& Strang, 2008). Although housing may be more affordable in outer-urban and rural areas, public transport options are few and there can be considerable distances to travel to access services, education and employment 
opportunities, as well as visit family and friends. In these circumstances, a driver's licence and access to a car becomes indispensable to avoid social exclusion and isolation (Barber, 2007; Correa-Velez, Barnett, \& Gifford, 2013; Olliff, 2010).

Australian driving conditions may differ vastly from those previously encountered by refugees and many will have had no previous formal driving lessons (Haworth, Symmons, \& Kowadlo, 2000). While practice is vital, opportunities are limited due to the high cost of formal lessons or the need to know someone with a car and a permanent licence (VicRoads, 2012a). For drivers under the age of 21, the Victorian Government requirement of 120 hours of documented driving practice is particularly difficult to satisfy. Furthermore, driver education material is unlikely to be available translated into the required community languages (Haworth et al., 2000).

There are some Australian community-based programs that attempt to address these barriers. For example, in Victoria, VicRoads provides the cost-free L2P learner driver mentor program across 55 municipalities to assist those under 21 years of age (VicRoads, 2012b). L2P programs typically have 10\% culturally diverse participants but exclude older learners. Several localities of high cultural diversity provide 'Focused' L2P programs that target refugee participants (Australia College of Road Safety, 2012). The Youth Driving Program in the ACT aims to support relationships between police and refugee youth by engaging Police Officers as driving mentors (Department of Immigration and Citizenship, 2012). In Queensland, Job Ramp provides a buddy system where two refugee participants share a onehour driving lesson, each driving for half the lesson and as a passenger for the other half. The buddy system also provides the opportunity for those with poorer English to be supported by someone with English language skills (Life and Career Centre, 2008). Other Australian programs that address refugee-specific needs include the Skills to Empower program in Geelong; (Diversitat, 2011) Drive to Thrive in Melbourne; (Spectrum Migrant Resource Centre, 2012) the SCARF L2P Driving Program in Wollongong; (SCARF, 2012) and the Learner Driver Project for Humanitarian Entrants in Wagga Wagga (Multicultural Community Council of Wagga Wagga, 2012).

There is no published evidence however, for the effectiveness and impact of these programs, although reports of American programs suggest that such initiatives have assisted refugees to gain their licences and may have reduced accidents and traffic violations (Barker, 2011; Refugee Development Center, 2011). The Refugee 
Council of Australia argues that a 'concerted national strategy is required as well as more research on effective local approaches to driver training which could be replicated to support refugees obtaining their licence' (Refugee Council of Australia, 2009).

The Latrobe Community Health Service (LCHS) initiated the Latrobe Valley Newly Arrived Driver Education Program (LVNADEP) in regional Victoria in partnership with local stakeholder agencies. This resulted from a consultation with 51 refugee-background community members living in the region, approximately two hours' drive east of Melbourne. Consultations identified that although most held a learner's permit they did not have the means to practise driving. Community members indicated their willingness to learn, their desire to drive safely and avoid accidents and court appearances.

The program model comprised six weeks of theory classes delivered by Victoria Police, followed by 'driving skills' with a qualified driving instructor before participants were matched with a volunteer mentor driver. Mentors complete a training session covering cultural awareness, road safety and effective mentoring. The mentors receive a report from the driving school instructor to assist in planning the practice sessions. The mentor works with the mentee until they are ready for their road test.

This paper presents a summary of the evaluation findings from interviews with nine program mentees from diverse African backgrounds and two mentors.

\section{Importance of having a driver's licence and benefits of the program}

Four of the evaluation participants obtained a driver's licence. Living in regional Victoria without a driver's licence or a car posed a range of difficulties for mentees, limiting mobility and employment opportunities. Mentees reported that public transport was unreliable and a mentor expressed surprise at the public transport challenges that refugees faced, as it had been 30 years since he had used it. All mentees felt that not having a driving licence was a disadvantage and reported that a lack of driving skills limited both their ability to work and the choice of employment. Mentees described being unable to afford driving lessons as they were unemployed, but unable to apply for jobs without a licence. One reported losing a job as a consequence of not having a licence. 
It really changed things in my life because since when I get my driving licence, any place I wish to go I can go without any problem and also if there is any position advertised in Melbourne I can go without any delay. (Mentee)

A licence also meant mentees were independent and could help their family and friends when needed. It was important for some mentees to have a driving licence as a form of official photo identity so they did not have to carry their passport with them.

Mentees and mentors described benefits from the program including obtaining a driver's licence, the cost-free participation, meeting new people and the opportunity to volunteer.

The best thing is of course the driving mentors to educate the people and then people will get their licence and their lives will become better and easier. (Mentee)

In addition to financial constraints, not knowing someone with a car and willing to teach them to drive was a major barrier. Mentees reported negative experiences from private driving instructors who 'took advantage' and over-charged them while failing to teach driving skills as they were always 'rushed' and 'not helpful'.

...took from me $\$ 950$ and I did not get any licence. I got licence here in Latrobe program. (Mentee)

Conversely, mentors were described as friendly, patient and able to teach the knowledge and skills participants needed to become safe and confident drivers. The mentees felt a sense of security from the Program because of the organisations involved. All mentees and mentors reported that the program provided opportunities to meet new people. The mentors noted the importance of spending time getting to know and establishing trust with mentees who were often shy. Mentees became friends with one another and mentors met their mentee's family. Mentors felt volunteering provided an avenue for giving back to their community and they were gratified when mentees succeeded.

When they get their licence you see the look on their face. I like that part of it. (Mentor) 
Mentors noted the importance of the cultural awareness training in providing them with confidence to work with the refugee-background mentees and one mentor indicated that he would not have volunteered without it. The mentors also reported that although they were aware of the difficulties refugees can face; volunteering in the program provided them with a greater understanding of refugee experiences.

\section{Program challenges, barriers to participation and suggested improvements}

Both mentees and mentors reported communication challenges such as scheduling lesson times, but the greatest barrier to successful participation was insufficient numbers of mentors to match the demand of the mentees. Some were frustrated by waiting more than two years to participate.

... you tell the immigrant...you will get the program within four weeks when you register instead of two years so people will not have that patience ... they always tell you the list is this long you have to wait. (Mentee)

The consequent intermittent nature of lessons also meant that mentees forgot what they had learned in between sessions. One mentee who owned a car reported that he drove without a licence after waiting more than two years for a lesson, but had an accident and stated he would not drive again until he had a licence. Despite criticism of private driving instructors, mentees suggested that when mentors could not be provided, vouchers or subsidised driving lessons would be helpful. One mentor reported that making time for the program and fitting it in with their own work was a challenge. There were also problems with booking the program vehicle. The mentees reported that they accessed extra driving lessons from their social networks, usually from their church. The mentors perceived their mentees were initially afraid of driving alone with a stranger as well as lacking driving confidence and speaking English. Mentors reported some mentees had difficulty concentrating while driving. Mentors also reported that participants need to take some responsibility and acknowledge the commitment the volunteers have made to teach them to drive and that mentees needed to be flexible to suit the mentors.

They chop and change at the drop of a hat...they do themselves an injustice by not putting themselves out to fit in with our timetables as well. (Mentor) 
Mentors suggested that program training for mentees should include time management and communication - including information in their first language on how to reschedule a lesson. They acknowledged that mentees did not always have credit on their mobile phones and this could aggravate communication difficulties. Mentees and mentors felt that communicating in English was a challenge for understanding driving instructions. In these situations mentors described using hand signals to communicate directions and a mentee suggested mentors could repeat instructions.

\section{Discussion, conclusion and limitations}

Although the program helped some participants to gain a licence and also showed potential to build social connectedness, a lack of mentors was a major impediment. Obtaining a drivers licence was a high priority for many refugees, however, often such programs cannot keep up with the demand (Flanagan, 2007). Significant effort is required to recruit and maintain a pool of eligible volunteer mentors. The factors motivating a person to volunteer are complex but important to understand when attempting to attract, recruit and retain volunteers (Esmond \& Dunlop, 2004). Given that most driving practice was reported to have been obtained outside the program, a solution could be to recruit volunteers from the church and other community organisations. Since this evaluation, the program has been registered with Centrelink as an approved volunteer program so that people aged 55 years and over can credit 15 hours per week of volunteered time to meet requirements for welfare benefits. In a similar program, it was found that on average, refugee students took 63 hours of tuition to obtain their licence (Multicultural Community Council of Wagga Wagga, 2012). Mentors and mentees both reported that language was sometimes a barrier when giving driving instructions. Difficulties in learning English, particularly for refugees lacking literacy in first languages is recognised as challenging and also needs to be addressed (Beiser, 2009; Riggs et al., 2012).

The evaluation findings begin to address the scarcity of literature on refugee driver-education programs. The generalizability of these findings is limited however, by the small sample size and the fact that mentees were all of African background and may not represent other cultural groups. The sample of evaluation participants may also not represent the entire program participant group. In addition to difficulties 
locating participants, recruitment may have been hindered by disengagement from the program due to the long wait for a mentor.

Given that Australia's expanding refugee intake includes increasing numbers of people settling in rural and regional areas, evidence is needed for community services to implement settlement assistance programs. Volunteer driver education programs have the potential to provide valuable support and promote social inclusion but attention needs to be given to volunteer recruitment and retainment strategies, as well as monitoring program implementation. Gaining a licence is critical for refugee settlers, this innovative program helped to offset some of the barriers to achieving this.

\section{Acknowledgements}

This evaluation was funded by Latrobe Community Health Service and ethics was approved by the University of Melbourne Human Research Ethics Committee (1136487.1) and Latrobe Community Health Service. Elisha Riggs and Karen Block were supported by the Jack Brockhoff Child Health and Wellbeing Program. Elisha Riggs was supported by the Murdoch Childrens Research Institute at the time of preparing the manuscript which is supported by the Victorian Government's Operational Infrastructure Support Program.

\section{References}

Ager, A., \& Strang, A. (2008). Understanding integration: A conceptual framework. Journal of Refugee Studies, 21(2), 166-191. doi: 10.1093/jrs/fen016

Australia College of Road Safety. (2012). Special issue - 2012 conference a safe system: Expanding the reach! Journal of the Australasian College of Road Safety, 23(4).

Barber, G. (2007). Road and driver safety in the Victorian Sudanese community: Exploring the issue from perspectives of service providers: School of Public Health, La Trobe University.

Barker, D. (2011, July 9). Refugees driving better in Morgan, The Fort Morgan Times.

Retrieved from http://www.fortmorgantimes.com/ci 18441018?|ADID=Searchwww.fortmorgantimes.com-www.fortmorgantimes.com

Beiser, M. (2009). Resettling refugees and safeguarding their mental health: Lessons learned from the Canadian Refugee Resettlement Project. Transcultural psychiatry, 46(4), 539-583. doi: 10.1177/1363461509351373 
Correa-Velez, I., Barnett, A. G., \& Gifford, S. (2013). Working for a better life: Longitudinal evidence on the predictors of employment among recently arrived refugee migrant men living in Australia. International Migration. doi: 10.1111/imig. 12099

Department of Immigration and Citizenship. (2012). Taking the initaitive: Youth driving program. Retrieved from http://www.immi.gov.au/gateways/police/case-studies/act/youth-driving/

Diversitat. (2011). Helping refugees in the community. Retrieved from http://www.volunteeringgeelong.org.au/home/index.php?option=com content \&task=blogcategory\&id=37\&ltemid=57

Esmond, J., \& Dunlop, P. (2004). Developing the volunteer motivation inventory to assess the underlying motivational drives of volunteers in Western Australia. Australia: CLAN WA Inc.

Flanagan, J. (2007). Dropped from the moon: The settlement experiences of refugee communities in Tasmania. Hobart, Tasmania: Social Action and Research Centre, Anglicare Tasmania.

Haworth, N., Symmons, M., \& Kowadlo, N. (2000). Road safety issues for people from non-English speaking backgrounds. Monash University Accident Research Centre.

Life and Career Centre. (2008). Jobs for refugees and migrants project (Jobs Ramp). Toowoomba, Queensland: Leading Australia Foundation Ltd.

Multicultural Community Council of Wagga Wagga. (2012). Pilot learner driver project for humanitarian entrants. Retrieved from http://www.immi.gov.au/media/publications/settle/empowering refugees/ pdf/ 11-pilot-learner-driver-project.pdf

Olliff, L. (2010). What works: Employment strategies for refugee and humanitarian entrants. Refugee Council of Australia.

Refugee Council of Australia. (2009). Australia's refugee and humanitarian program Community views on current challenges and future directions.

Refugee Development Center. (2011). Refugee driving simulator. Retrieved from http://www.refugeedevelopmentcenter.com/?page id=22

Riggs, E., Block, K. , Gibbs, L. , Davis, Elise , Szwarc, J , Casey, S. , . . Waters, E. (2012). Flexible models for learning English are needed for refugee mothers. Australian Journal of Adult Learning, 52(2), 397-405.

SCARF. (2012). L2P Driving Program. Retrieved from http://www.scarf1.org.au/ourprograms\#! our-programs/vstc4=skills-\&-training

Spectrum Migrant Resource Centre. (2012). Drive to thrive. Retrieved from http://www.spectrumvic.org.au/Settlement-Family/Drive-to-Thrive

VicRoads. (2012a). How to get your car probationary licence. Retrieved from http://www.vicroads.vic.gov.au/Home/Licences/GetYourPs/Howtogetyourprob ationarycarlicence.htm

VicRoads. (2012b). L2P - learner driver mentor program. Retrieved from http://www.vicroads.vic.gov.au/Home/Licences/GetYourPs/PreparingForYourL icenceTest/L2P.htm 


\section{Biographical notes}

Elisha Riggs is a Research Fellow co-leading the Refugee and Migrant Research Program in the Healthy Mothers Healthy Families Research Group at the Murdoch Childrens Research Institute. With a background in public health and health promotion her research experience includes understanding the social determinants of health, addressing health inequalities, and the implementation and evaluation of interventions. Her research utilises participatory methodologies in partnership with communities and diverse stakeholders.

Karen Block is a Research Fellow in the Academic Centre for Health Equity, Melbourne School of Population and Global Health. She is experienced in qualitative methodologies and mixed methods research in education settings and is currently working on a range of projects involving children and families with a focus on social inclusion, refugee and migrant populations, evaluating complex interventions and working in collaborative partnerships with the community.

Taffie Mhlanga was the Health Promotion Officer who conducted the evaluation at Latrobe Valley Community Health Service. He has a background in public health and is committed to working with the community to improve their health and settlement experiences.

Christina Rush is the Manager of Primary Prevention at Latrobe Community Health Service. She is currently the Board Chair of Gippsland Women's Health Service Council and her previous appointments include Manager of the School Nursing program with Department of Education and Early Childhood Development, and a variety of senior roles, managing teams and stakeholders for the Department of Human Services.

Mollie Burley, a Senior Lecturer in the Monash University Department of Rural \& Indigenous Health (MUDRIH) in the School of Rural Health where she leads the Interprofessional Collaboration Team. She holds a Master of Rural Health (Research) and is dedicated to improving rural health practice and supporting her rural colleagues. Her current passion is focussed on interprofessional collaboration 
in healthcare specifically in assisting educators and clinicians improve their practice with more effective collaborative team working. 